\title{
La salina de Biomaris (Isla Cristina). La última instalación artesanal de la costa onubense
}

Daniel Martínez Castizo | historiador y antropólogo

URL de la contribución <www.iaph.es/revistaph/index.php/revistaph/issue/view/4256>

\section{RESUMEN}

Desde la antigüedad, la costa de Huelva se ha caracterizado por una intensa y dinámica actividad salinera. Hoy día, la única instalación que de forma activa da fe de dicho pasado es la salina de Biomaris en Isla Cristina. Esta instalación es heredera de la industria salazonera que, desde el siglo XVIII y hasta mediados de siglo XX, transformó la economía del territorio y configuró un particular paisaje de muros, esteros y calentadores en el interior de las marismas onubenses. Para poder sobrevivir a la dura competencia del sector industrial, Biomaris apostó en 2005 por la revalorización del patrimonio paisajístico y cultural salinero, así como por conservar la producción artesanal e introducir nuevos productos.

\section{Palabras clave}

Biomaris | Ecoturismo | Isla Cristina (Huelva) | Producción artesanal | Revalorización | Sal | Salinas | 


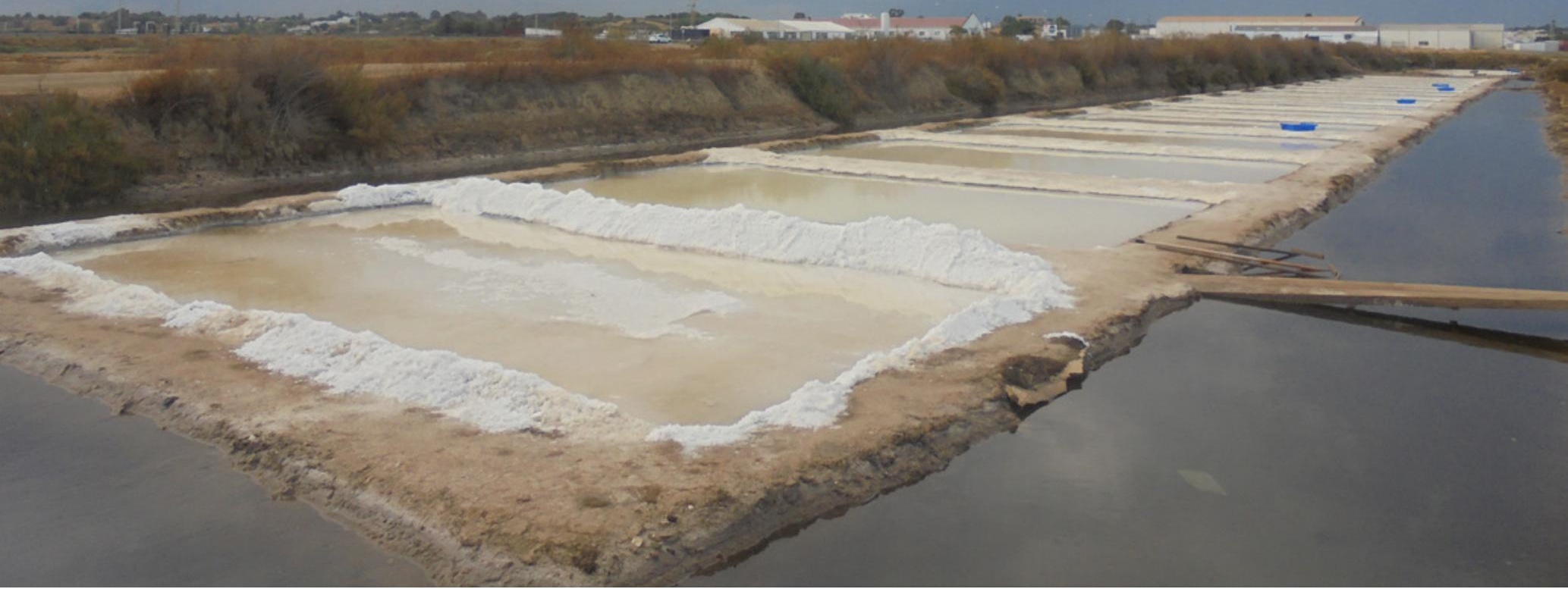

Eras de precipitación desde la que se extrae la Flor de sal | foto Daniel Martínez Castizo, 2017, autor de todas las imágenes que ilustran esta contribución 
En el paraje natural Marismas de Isla Cristina, entre el Caño del Puntal y el Placerón, se encuentra ubicada la salina de Biomaris, la última instalación salinera de la costa onubense que mantiene la actividad tradicional en el cosechado de la sal.

Esta pequeña salina, cuyas dimensiones no van más allá del kilómetro cuadrado, se ha convertido en todo un símbolo de resistencia y representatividad de lo que un día fue el patrimonio salinero en esta parte del Golfo de Cádiz. Y es que, desde Ayamonte hasta la desembocadura del Guadalquivir, entre los siglos XVIII y XIX, la costa se fue plagando de salinas al socaire de la industria salazonera que catalanes y levantinos habían introducido en torno al boquerón, la sardina y el atún.

A comienzos de siglo XX ya se había alcanzado el punto álgido con la consolidación de 22 salinas para, desde la década de los cincuenta, empezar una progresiva decadencia provocada por la reducción de los caladeros, la incapacidad competitiva de las salinas frente a las modernas industriales y la aparición de nuevos métodos de procesado y conservación de alimentos.

Puntualmente se viviría unos años de repunte asociado al hambre de la posguerra que disparó la demanda de sardinas en salazón. Además, el Estado franquista permitió la instalación de sociedades y altos mandos nazis en diferentes sectores productivos como medio de pago económico y político a los préstamos efectuados (372 millones de marcos según convenio MadridBerlín de agosto de 1941), por la Alemania del III Reich.

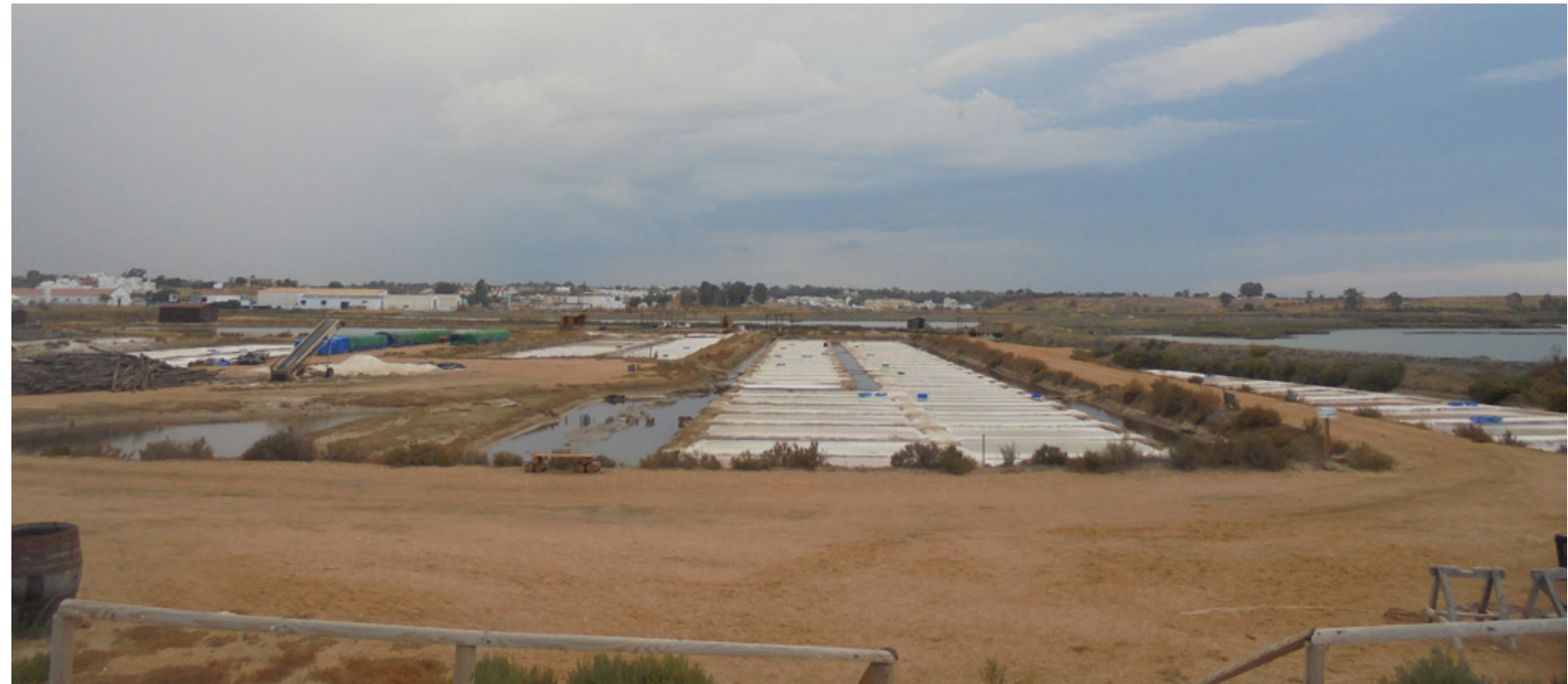




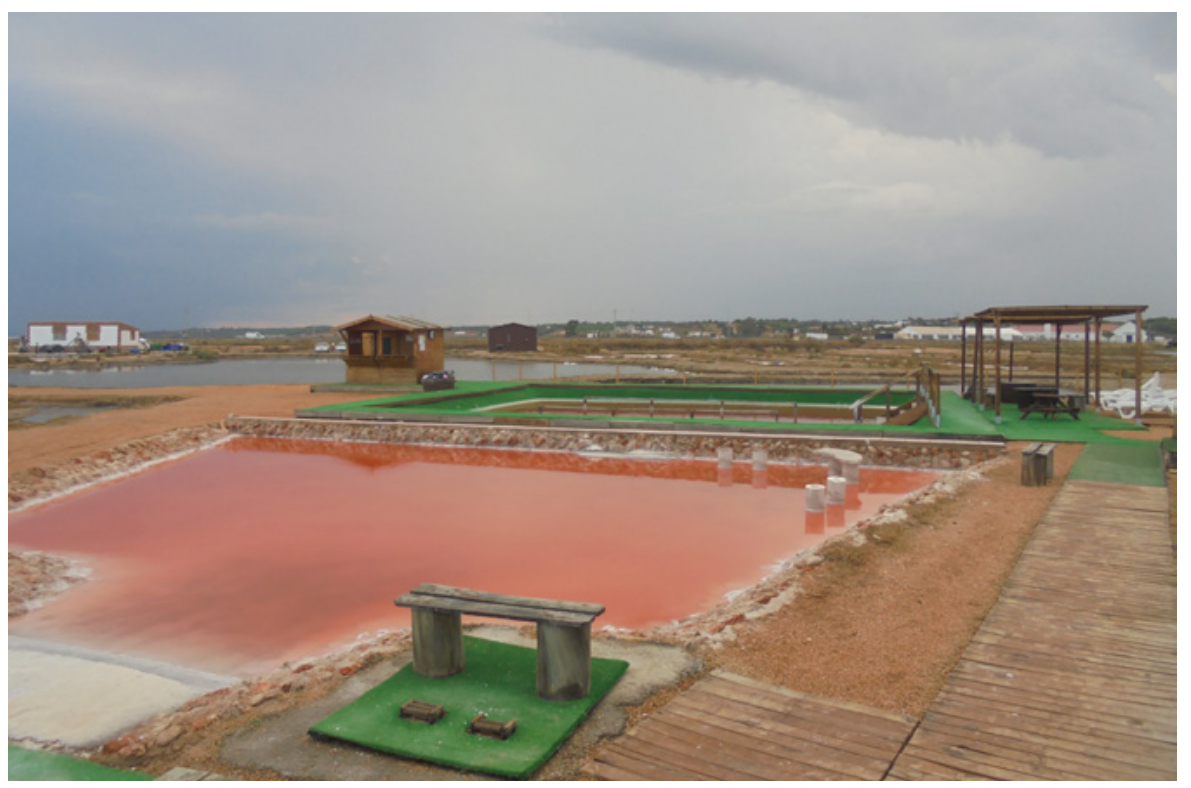

A través de este contexto se explica la aparición en Isla Cristina de Adolf Clauss (jefe de la Abwehr), conocido en la localidad como "Juan El Alemán". En 1954 Clauss llega a la localidad como representante de la empresa de cosméticos alemana Biomaris, una compañía interesada en la obtención de sal para su exportación. Un año después, el "empresario" logra que la salina se encuentre en funcionamiento con la particularidad de que la cristalización, para lograr una mayor pureza en cloruro de sodio, tenía lugar en lebrillos y no en eras de precipitación.

A la muerte de Clauss, es Manuel Rodríguez, maestro salinero de Biomaris, quien se hace con las riendas de las instalaciones y reorienta la producción hacia la sal gorda que puede colocar en las fábricas salazoneras de Isla Cristina y Ayamonte. Durante casi 40 años mantiene viva las instalaciones, asiste a la desaparición del resto de salinas artesanales -convirtiéndose así en el único ejemplo activo del pasado salinero onubense-, y contempla con resignación la aparición de un duro competidor industrial como es Marismas del Odiel.

En 2003 la propiedad pasa a su hija Manuela, quien para sostener la herencia se suma a la incipiente generación de nuevos salineros del medio rural que, como en el resto de Europa, reorientan la producción hacia nuevos productos y aprovechamientos.

Para ello y, en primer lugar, decide mantener como seña de identidad la producción artesanal con la creación de la sociedad "Flor de Sal Salinas de Isla Cristina-Biomaris", a través de la cual apostará por la calidad y no la can-



Aperos tradicionales de cosecha y pesca 




tidad. Posteriormente se centra en la revalorización de las potencialidades naturales del entorno (visitas guiadas y talleres de sal); también amplía la oferta de servicios (baños de magnesio); así como la línea de productos derivados de la sal (flor y escamas de sal; salmuera, aceite, sal y jabón de magnesio; y hasta 35 tipos de sal con distintas especias). En definitiva, apuesta por un aprovechamiento responsable y sostenible del medio natural del que salen casi 300 T/año de sal artesanal.

Además, desde 2011, Biomaris pasó a formar parte (junto con otras 10 salinas de España, Francia, Portugal y Reino Unido), del proyecto EcoSal Atlantis a través de la Ruta Sal Tradicional Ruta del Atlántico. Este programa, cuya base fundamental es la potenciación del ecoturismo y la consolidación así de la actividad en el territorio, pone de relieve la mejora de la gestión de los respectivos paisajes salinos mediante la investigación, el intercambio de experiencias y la colaboración de las instituciones y agentes locales.

De esta forma, la salina de Biomaris, sin renunciar a su legado patrimonial pues las instalaciones siguen siendo las mismas que entre muros de piedra y salicornia se viene trabajando desde hace más de 60 años-, y mediante un inteligente proceso de revalorización y diversificación, ha logrado consolidarse y ser reconocida como una de las actividades económicas más importantes de la provincia de Huelva. 


\section{BIBLIOGRAFÍA Y OTRAS FUENTES}

- ECOSAL ATLANTIS <http://ecosal-atlantis.ua.pt/ index.php?q=es/content/lista-de-actividades> [Consulta: 05/09/2018]

- FLOR DE SAL BIOMARIS <http://flordesalbiomaris. com> [Consulta: 05/09/2018]

- GOZÁLVEZ ESCOBAR, J. L. (2017) El final de las salinas artesanales. En CAMPOS, J. M. (coord.) El patrimonio histórico y cultural en el Paraje Natural Marismas del Odiel. Huelva: Servicio de Publicaciones de la Universidad de Huelva, 2017, pp. 390-404

- PAISAJE de Interés Cultural pesquero de Isla Cristina (Huelva) [en línea] Instituto Andaluz del Patrimonio Histórico, $2005<$ http://www.iaph.es/export/sites/default/ galerias/patrimonio-cultural/documentos/paisaje-cultural/ huelva/paisaje_interes_cultural_pesquero_isla_cristina_ huelva.pdf> [Consulta: 05/09/2018]

- PATRIMONIO cultural en los puertos de interés pesqueros en Andalucía. Isla Cristina (2013-2015) [en línea] En Atlas del Patrimonio Cultural en los Puertos de Interés Pesquero de Andalucía. Universidad de Sevilla, Consejería de Fomento y Vivienda. Agencia Pública de Puertos de Andalucía, 2013-2015 <http://grupos.us.es/ puertosandaluces/pdf/Ficha_IslaCristina.pdf> [Consulta: 05/09/2018]

- RUBio garcía, J. C.; SERVETO AGUILÓ, P. (2004) Historia de las salinas del Golfo de Cádiz. En PÉREZ, A. (coord.) Salinas de Andalucía. Sevilla: Junta de Andalucía, 2004, pp. 42-46

- Rubio garcía, J. C.; SERVETO AGuiló, P. (2004) Tipos funcionales de las salinas atlánticas: salinas artesanales y salinas industriales. En PÉREZ, A. (coord.) Salinas de Andalucía. Sevilla: Junta de Andalucía, 2004, pp. 177-190

- SOlER GARCÍA, M. Espionaje en Huelva: Operación Mincemeat. El hombre que nunca existió [en línea] <http://www.culturandalucia.com/gce/operaci\%C3\%B3n mincemeat_el_hombre_que_nunca_existi\%C3\%B32.htm> [Consulta: 05/09/2018] 